\title{
Physicochemical and Spectroscopic Characterization of Yeast Extract Powder After the Biofield Energy Treatment
}

\author{
Mahendra Kumar Trivedi ${ }^{1}$, Alice Branton ${ }^{1}$, Dahryn Trivedi ${ }^{1}$, Gopal Nayak ${ }^{1}$, Khemraj Bairwa ${ }^{2}$, \\ Snehasis Jana ${ }^{2, *}$ \\ ${ }^{1}$ Trivedi Global Inc., Henderson, NV, USA \\ ${ }^{2}$ Trivedi Science Research Laboratory Pvt. Ltd., Bhopal, Madhya Pradesh, India
}

Email address:

publication@trivedisrl.com (S. Jana)

\section{To cite this article:}

Mahendra Kumar Trivedi, Alice Branton, Dahryn Trivedi, Gopal Nayak, Khemraj Bairwa, Snehasis Jana. Physicochemical and Spectroscopic Characterization of Yeast Extract Powder After the Biofield Energy Treatment. American Journal of Life Sciences. Vol. 3, No. 6, 2015, pp. 387-394. doi: 10.11648/j.ajls.20150306.12

\begin{abstract}
Yeast extract powder (YE powder) is particularly used in culture media for the cultivation of microorganisms found in milk or other dairy products. The present study was intended to explore the influence of biofield energy treatment on the physicochemical and spectral properties of YE powder. The study was accomplished in two groups; first group was remained as control, while another was subjected to Mr. Trivedi's biofield energy treatment and termed as the treated group. Afterward, both the samples were evaluated using several analytical techniques. The X-ray diffractometry (XRD) study showed the halo patterns of XRD peaks in both the samples. This indicated the amorphous nature of the samples. The particle size study revealed the $4.77 \%$ and $26.28 \%$ increase $d_{50}$ (in the average particle size) and $d_{99}$ (particle size below that $99 \%$ particles are present), respectively of treated YE powder with respect to the control. The surface area analysis showed the $14.06 \%$ increase in the specific surface area of treated sample with respect to the control. The differential scanning calorimetry (DSC) analysis exhibited the $41.64 \%$ increase in the melting temperature of treated YE powder sample as compared to the control. The TGA/DTG analysis exhibited the increase in $\mathrm{T}_{\text {onset }}$ (onset temperature of thermal degradation) by $7.51 \%$ and $12.45 \%$ in first and second step of thermal degradation, respectively in the treated sample as compared to the control. Furthermore, the $\mathrm{T}_{\max }$ (maximum thermal degradation temperature) was increased by $4.16 \%$ and $24.79 \%$ in first and second step of thermal degradation, respectively in the treated sample with respect to the control. The Fourier transform infrared (FTIR) study revealed the changes in the wavenumber of functional groups such as C-H (stretching) from $2895 \rightarrow 2883 \mathrm{~cm}^{-1}$ and $2815 \rightarrow 2831 \mathrm{~cm}^{-1}$, respectively; C-N from $1230 \rightarrow 1242 \mathrm{~cm}^{-1}$; and C-O stretching from 1062-1147 $\mathrm{cm}^{-1} \rightarrow 1072-1149 \mathrm{~cm}^{-1}$ of treated YE powder sample as compared to the control. The UV-vis spectroscopy showed the similar patterns of absorbance maxima $\left(\lambda_{\max }\right)$ in both the control and treated samples. Therefore, the analytical results suggested the considerable impact of Mr. Trivedi's biofield energy treatment on physicochemical and spectral properties of YE powder. The increase in $T_{\text {onset }}$ and $\mathrm{T}_{\max }$ after the biofield treatment suggests that the treated YE powder might be more effective in culture medium than the control YE powder.
\end{abstract}

Keywords: Yeast Extract Powder, the Trivedi Effect, Particle Size Analysis, Surface Area Analysis, Thermogravimetric Analysis, Fourier Transform Infrared Spectroscopy

\section{Introduction}

Yeast extract powder (YE powder) is the common name used for several forms of processed yeast products [1]. It is prepared from selected strain of Saccharomyces under precise condition, in order to retain all the nutritive values, vitamins (especially B complex), amino acids, and growth factors $[2,3]$. It is used as food additive, flavoring agent, or as nutrient in culture media for the cultivation of microorganisms, which encounter in milk or other dairy products. It is also used along with beef extract or in place of beef extract in the growth medium $[4,5]$. The yeast extracts and fermented foods contain mainly glutamic acid, which in solution form with sodium ion is equivalent to the monosodium glutamate [6]. Owing to numerous controversies associated to monosodium glutamate, the food 
manufacturers write yeast extract on food packaging label instead of monosodium glutamate [7]. Sterilization of culture medium plays a significant role on its quality. Sterilization by autoclaving is the common technique during the preparation of culture medium [8]. However, the extreme heat treatment of complex culture media may result in demolition of the nutrients either by chemical reactions among the components or by direct thermal degradation [9]. Hence, a technique is required that can improve the overall stability of the $\mathrm{YE}$ powder.

Recently, the energy therapies have been reported for beneficial effects in the several fields throughout the world. Biofield energy treatment is one of the energy therapy that been a crucial part of shamanic and other healing practices for as long as existed human societies [10, 11].

The National Center for Complementary and Alternative Medicine (NCCAM) defines the biofield therapies as manipulation of various energy fields (measurable or putative) to affect the health. Practices based on putative energy fields include qi gong, reiki, therapeutic touch, and healing touch [12]. Similarly, the biofield energy treatment is also a putative energy therapy that has been recently reported in several fields for its usefulness [13-15].

Several hypotheses have been proposed to explain the mechanisms of the energy medicine such as healer interventions, electromagnetic therapies, bioelectromagnetics, biophoton emission, bioelectromagnetic information, etc. [16]. According to the theory of consciousness and theory of physical resonance, the healer's intent to heal, that may interact with the physical realm $[16,17]$; and according to physical resonance theory, the energy can be exchanged between the energy fields of healer and patient [18]. Thus, the human can harness the energy from universe and transfer it to the object (living or non-living). Mr. Mahendra Kumar Trivedi is the well-known practitioner of biofield energy treatment (The Trivedi Effect ${ }^{\circledR}$ ) that has been studied in the several fields including the microbiology research [13], biotechnology research [14], agricultural science research [15], etc. Additionally, The Trivedi Effect ${ }^{\mathbb{B}}$ has been also reported to alter the various properties such as particle size, surface area, crystallite size, thermal and spectral properties of organic compounds [19] and organic products [20].

Therefore, based on the outstanding impact of biofield energy treatment in several areas, the present study was aimed to explore the effect of biofield energy treatment on the physicochemical and spectral properties of YE powder. The treated YE powder was analyzed using various analytical techniques such as X-ray diffractometry (XRD), particle size analysis, surface area analysis, differential scanning calorimetry (DSC), thermogravimetric analysis/derivative thermogravimetry (TGA/DTG), Fourier transform infrared (FT-IR), and UV-vis spectroscopy.

\section{Materials and Methods}

The certified yeast extract (YE) powder was obtained from HiMedia Laboratories, India. The YE powder was divided into two parts; first part was considered as control (without biofield energy treatment) and second part was handed over in sealed pack to Mr. Trivedi for the biofield energy treatment. Mr. Trivedi rendered the biofield energy treatment to the treated group through his unique thought transmission process under standard laboratory conditions. Afterward, the treated and control samples were evaluated for physicochemical analysis using XRD, particle size analysis, surface area analysis; thermal analysis by DSC and TGA/DTG; and spectral analysis by FT-IR and UV-vis spectroscopy.

\subsection{XRD Study}

The X-ray diffraction studies of control and treated YE powder samples were carried out on PW 1710 Phillips Holland diffractometric instrument. The XRD system was equipped with nickel filter and $\mathrm{CuK} \alpha$ radiation of $\lambda=$ $1.54056 \AA$.

\subsection{Particle Size Analysis}

The particle size of control and treated YE powder sample was characterized using a laser diffraction particle size analyzer (HELOS/BF, Sympatec GmbH, Germany). The detection limit of instrument was set in the range of 0.1-875 $\mu \mathrm{m}$. The raw data were acquired in the form of chart (cumulative percentage versus particle size in $\mu \mathrm{m}$ ). The percent alteration in particle size was calculated using the following equation.

$$
\begin{aligned}
& \% \text { change in particle size, } d_{50} \\
& =\frac{\left[\left(d_{50}\right) \text { Treated }-\left(d_{50}\right)_{\text {Control }}\right]}{\left(d_{50}\right) \text { Control }} \times 100
\end{aligned}
$$

Where, $\left(\mathrm{d}_{50}\right)$ Control and $\left(\mathrm{d}_{50}\right)$ Treated are the average particle size of control and treated samples, respectively; similarly the $d_{99}$ (particle size below which $99 \%$ of particle were present) was calculated.

\subsection{Surface Area Analysis}

The surface areas of control and treated YE powder were measured using the BET (Brunauer-Emmett-Teller) surface area analyzer by Smart SORB 90 at the liquid nitrogen temperature. The instrument limit was set from $0.2 \mathrm{~m}^{2} / \mathrm{g}$ to $1000 \mathrm{~m}^{2} / \mathrm{g}$. The deviation in the surface area of YE powder after the biofield energy treatment was calculated using the following equation.

$$
\% \text { change in surface area }=\frac{\left[\mathrm{S}_{\text {Treated }}-\mathrm{S}_{\text {Control }}\right]}{\mathrm{S}_{\text {Control }}} \times 100
$$

Here, $\mathrm{S}_{\text {Control }}$ is the surface area of control sample, while $\mathrm{S}$ Treated is the surface area of treated sample.

\subsection{DSC Study}

The YE powder samples i.e. control and treated were thermally analyzed using the Pyris 6 Perkin Elmer differential scanning calorimeter (Wellesley, MA, USA). The 
samples were weighed in the $50 \mu \mathrm{L}$ aluminum pans, then sealed hermetically and loaded in the DSC calorimeter at the room temperature. An identical empty pan sealed with cover lid was used as reference. The analytes were heated at the rate of $10^{\circ} \mathrm{C} / \mathrm{min}$ under the air flux of $5 \mathrm{~mL} / \mathrm{min}$. Subsequently, the melting temperature $\left(\mathrm{T}_{\mathrm{m}}\right)$ of both the control and treated samples were obtained from the DSC thermograms.

\subsection{TGA/DTG Analysis}

The TGA/DTG analysis of both control and treated YE powder samples were performed on Mettler Toledo simultaneous TGA/DTG STAR ${ }^{\mathrm{e}}$ SW 8.10 thermal analyzer. The analytes were heated from room temperature to $400^{\circ} \mathrm{C}$ at the heating rate of $5^{\circ} \mathrm{C} / \mathrm{min}$ under the air atmosphere. The onset temperature of thermal degradation $\left(\mathrm{T}_{\text {onset }}\right)$ and temperature at which maximum weight loss occurred $\left(\mathrm{T}_{\max }\right)$ in control and treated samples were found obtained from the TGA/DTG thermograms.

\subsection{FT-IR Spectroscopic Analysis}

The YE powder samples $(1 \% \mathrm{w} / \mathrm{w})$ were mixed with $\mathrm{KBr}$ powder and pressed to a disc. After that, the FT-IR spectra were recorded using Shimadzu's Fourier transform infrared spectrometer (Japan) in the frequency region of $500-4000 \mathrm{~cm}^{-1}$.

\subsection{UV-Vis Spectroscopic Analysis}

The UV-vis spectra of control and treated YE powder samples were recorded using the Shimadzu's UV spectrometer (2400 PC). The UV instrument was equipped with quartz cell of $1 \mathrm{~cm}$ with a slit width of $2.0 \mathrm{~nm}$. The samples were analyzed at the UV wavelength region of 200$400 \mathrm{~nm}$.

\section{Results and Discussion}

\subsection{XRD Analysis}

The XRD technique is generally used to study the crystallinity (crystalline or amorphous) in compounds like polymers, organic products or organic compounds. The diffraction of X-ray from the analyte provides the information on various quantitative physical structure characteristics like shape and dimension, distance among scattering centers and the extent of order in a given structural arrangement. Fig. 1 shows the X-ray diffractograms (Intensity versus $2 \theta$ curve) of YE extract (control and treated).

It showed the broad halo at $2 \theta$ equal to $19.4^{\circ}$ and $19.3^{\circ}$ in the control and treated sample, respectively. The halo patterns of XRD peaks revealed the amorphous form of both the control and treated samples [21]. The XRD study indicated that biofield energy treatment did not induce any alterations in the crystal structure of YE powder with respect to the control YE powder. It is well reported that the amorphous materials are the noncrystalline solids in which the atoms and molecules are disordered in a definite lattice pattern [22]. They possess the short-range order of atomic positions in crystals as like to liquids [23].

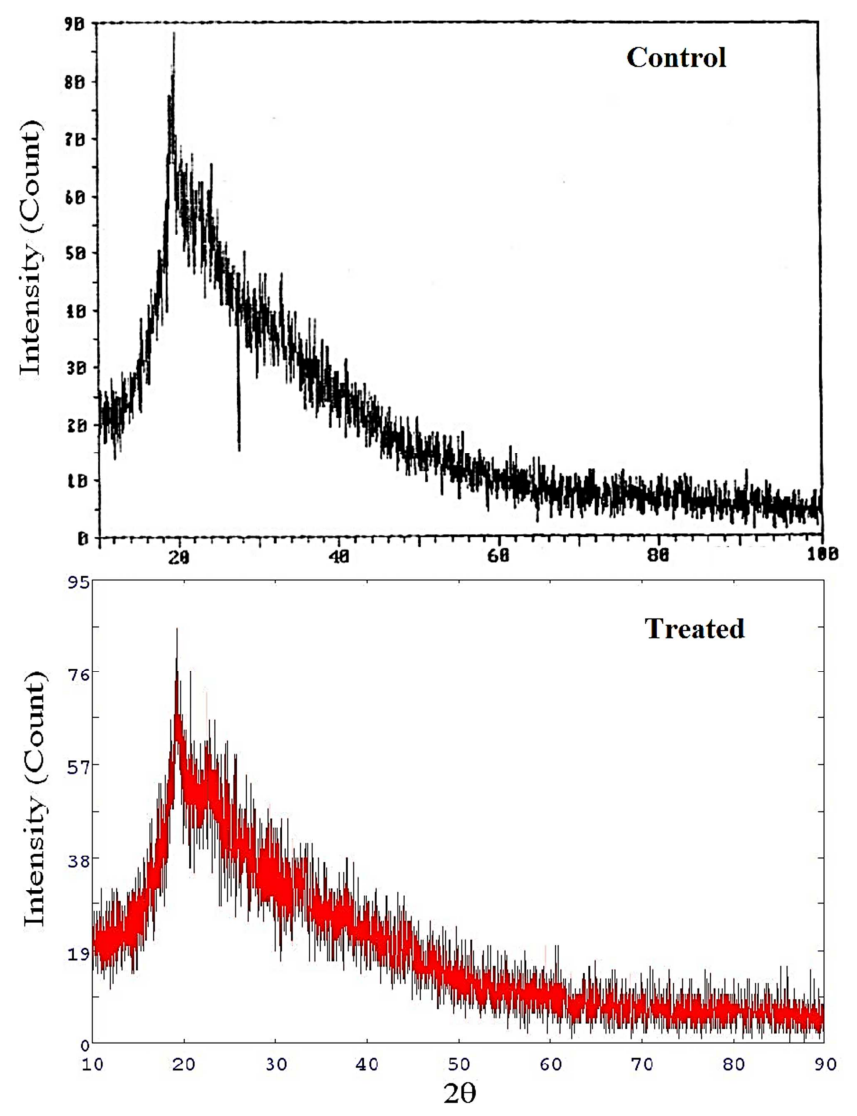

Figure 1. XRD diffractograms of control and treated yeast extract powder.

\subsection{Particle Size Analysis}

The particle size $d_{50}$ (average particle size) and $d_{99}$ (size exhibited by $99 \%$ of powder particles) in control and treated samples were measured by laser particle size analyzer. The particle size results of control and treated YE powder showed the $d_{50}$ as $24.93 \mu \mathrm{m}$ and $26.12 \mu \mathrm{m}$, respectively. The $d_{99}$ was observed as $118.33 \mu \mathrm{m}$ and $149.43 \mu \mathrm{m}$, in control and treated samples, respectively. The results showed about $4.77 \%$ increase in the $d_{50}$ and $26.28 \%$ increase in the $d_{99}$ of treated YE powder as compared to the corresponding control sample (Fig. 2).

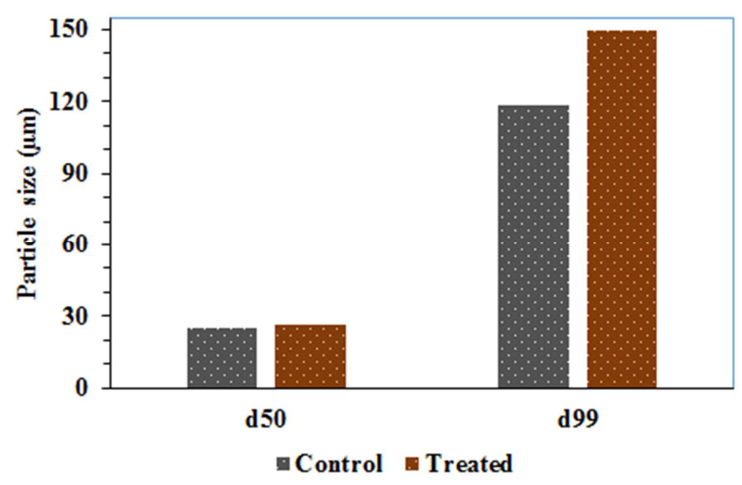

Figure 2. Particle size of control and treated yeast extract powder. 
It is hypothesized that the biofield energy treatment possibly leads to the agglomeration process in treated YE powder molecules, which may result in increased particle sizes $\left(d_{50}\right.$ and $\left.d_{99}\right)$ of treated sample. Recently, our group have reported the biofield-induced changes in the particle size of bile salt and proteose peptone [24].

\subsection{Surface Area Analysis}

The surface areas of control and treated YE powder samples were measured using the BET surface area analyzer. The surface areas of control and treated samples were found as $0.2184 \mathrm{~m}^{2} / \mathrm{g}$ and $0.2491 \mathrm{~m}^{2} / \mathrm{g}$, respectively. The result showed a significant increase in the surface area by $14.06 \%$ of treated sample with respect to the control YE powder (Fig. 3 ). It is well reported that the surface area is inversely proportional to the particle size [25]. Conversely, the results of present study were contrary to the above statement. This is only possible when the porosity has induced or increased in the particles of treated sample, which might lead to increase the effective surface area of respective sample [26]. Besides, due to enhance in surface free energy, the particles aggregate and form the larger size particles, which might also cause to increase in the particle size $\left(\mathrm{d}_{50}\right.$ and $\left.\mathrm{d}_{99}\right)$ with increase in the surface area [27]. Based on this, it is assumed that biofield energy possibly induced the aggregation of YE powder particle along with the enhanced porosity, which may lead to increase both the particle size and effective surface area of treated sample with respect to the control.

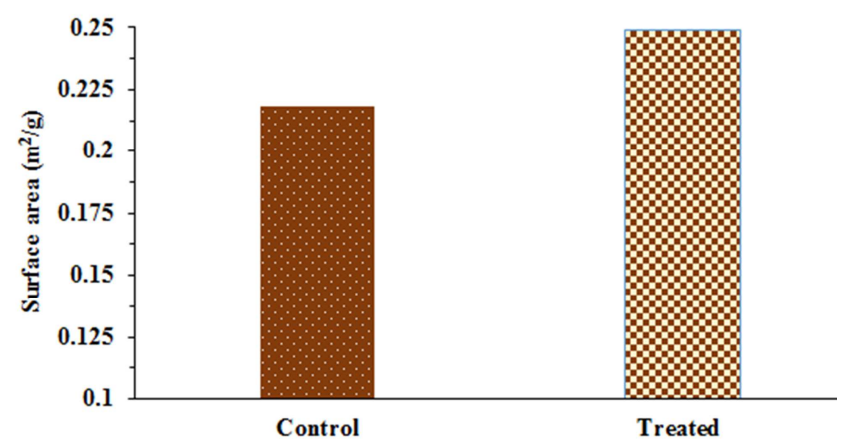

Figure 3. Surface area of control and treated yeast extract powder.

\subsection{DSC Analysis}

The DSC analysis was carried out to find out the melting temperature of YE powder (control and treated). DSC thermograms of control and treated YE powder are shown in Fig. 4. The melting temperatures of control and treated YE powder were detected around at $141.91^{\circ} \mathrm{C}$ and $201.00^{\circ} \mathrm{C}$, respectively (Table 1).

The results exhibited a significant increase in the melting temperature of treated sample by $41.64 \%$ with respect to the control. This increase in the melting temperature of treated sample might be associated to the enhancement of its thermal stability [28]. The increase in the melting point was occurred possibly due to increase in the particle size or due to stronger intermolecular attractions in the treated sample [29]. The results of thermal study suggested that the treated YE powder is more thermally stable than the control sample.

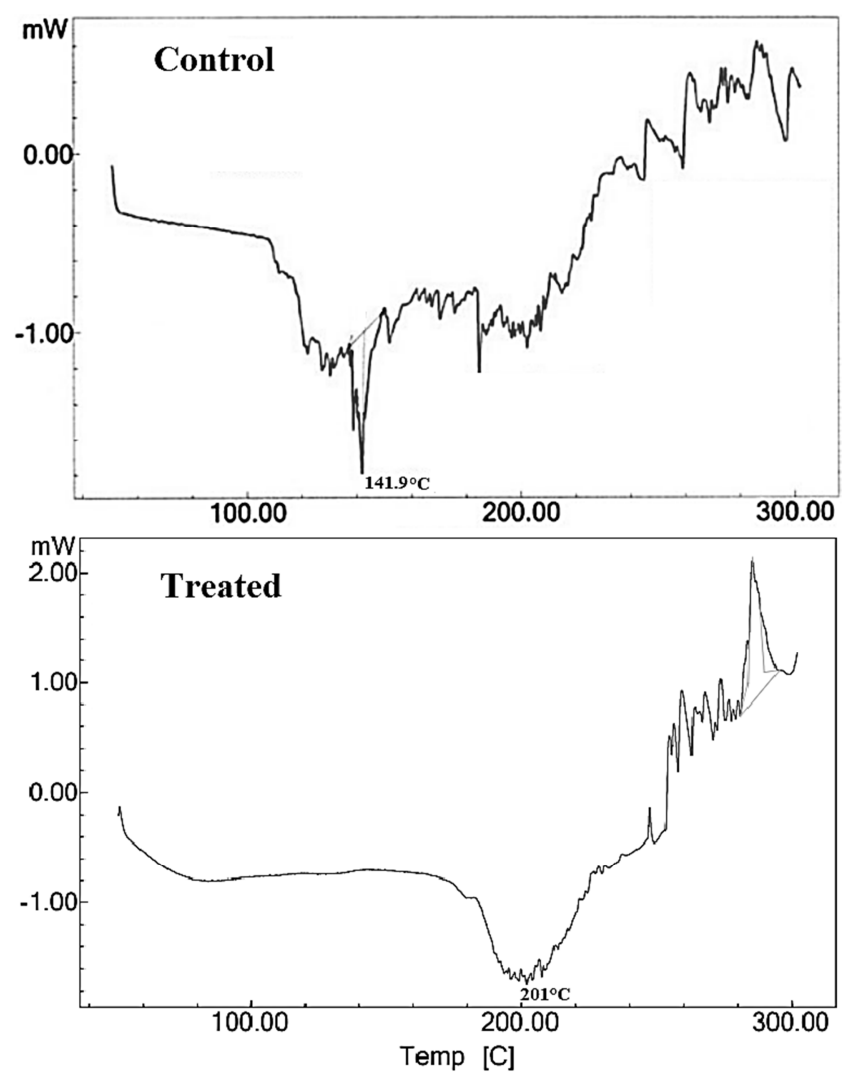

Figure 4. DSC thermograms of control and treated yeast extract powder.

Table 1. Thermal analysis of control and treated samples of yeast extract powder.

\begin{tabular}{lll}
\hline Parameter & Control & Treated \\
\hline Melting point $\left({ }^{\circ} \mathrm{C}\right)$ & 141.91 & 201.00 \\
Onset temperature $\left({ }^{\circ} \mathrm{C}\right)$ & 173.00 & 186.00 \\
& 265.00 & 298.00 \\
$\mathrm{~T}_{\max }\left({ }^{\circ} \mathrm{C}\right)$ & 208.43 & 217.11 \\
& 278.59 & 347.64 \\
\hline
\end{tabular}

$\mathrm{T}_{\max }$ : temperature at which maximum weight loss occurs

\subsection{TGA/DTG Analysis}

The TGA/DTG thermograms of control and treated YE powder are shown in Fig. 5, and data are summarized in Table 1. The TGA thermogram of control sample showed the two steps of thermal degradation process. The first step was started at $173^{\circ} \mathrm{C}\left(\mathrm{T}_{\text {onset }}\right)$ and terminated at $250^{\circ} \mathrm{C}\left(\mathrm{T}_{\text {endset }}\right)$; during this phase, the maximum thermal degradation $\left(\mathrm{T}_{\max }\right)$ was observed at $208.43^{\circ} \mathrm{C}$ and percent weight loss was found as $25.3 \%$. The second step was started from $265^{\circ} \mathrm{C}$ and terminated at $298^{\circ} \mathrm{C}$ with the $\mathrm{T}_{\max }$ of $278.59^{\circ} \mathrm{C}$ and percent weight loss of $10.31 \%$. The results showed the cumulative $35.61 \%$ weight loss during first and second step of thermal degradation in the control YE powder. Similarly, the treated sample also showed the two steps of thermal degradation. The first step was initiated at $186^{\circ} \mathrm{C}$, which was ended at $248^{\circ} \mathrm{C}$ with $\mathrm{T}_{\max }$ of $217.11^{\circ} \mathrm{C}$ and percent weight loss of 
$17.12 \%$. The second step was initiated at $328^{\circ} \mathrm{C}$ and terminated at $373^{\circ} \mathrm{C}$ with $\mathrm{T}_{\max }$ of $347.64^{\circ} \mathrm{C}$ and percent weight loss of $13.88 \%$. This showed the cumulative $31 \%$ weight loss in the treated sample during the first and second steps of thermal degradation. Overall, the TGA/DTG study revealed the increase in $\mathrm{T}_{\text {onset }}$ by $7.51 \%$ (in first step) and $12.45 \%$ (in second step) after the biofield treatment as compared to the control. Further, the $\mathrm{T}_{\max }$ was increased with
$4.16 \%$ and $24.79 \%$ in first and second step of thermal degradation in treated sample with respect to the control. The increase in $T_{\text {onset }}$ and $T_{\max }$ of both the steps in treated sample suggested the increased thermal stability of the treated sample as compared to the control [30]. Based on this, it is assumed that the biofield treated YE powder is more thermally stable than the control sample.
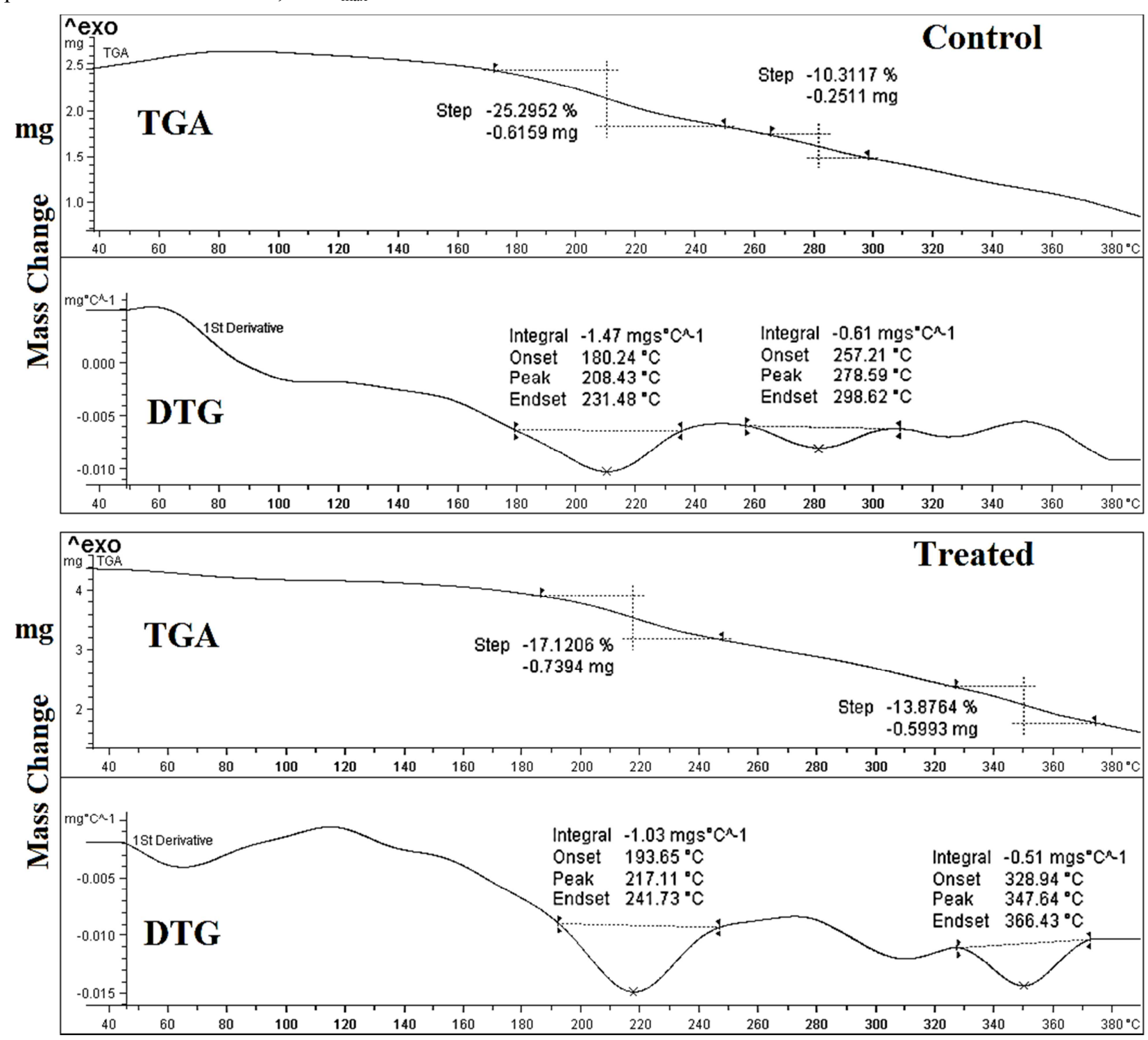

Figure 5. TGA/DTG thermograms of control and treated yeast extract powder.

\subsection{FT-IR Spectroscopic Characterization}

The FT-IR spectra of control and treated YE powder are shown in Fig. 6. The YE powder contains the vitamins, especially B-complexes, amino acids, and other growth factors [6]. Therefore, the FT-IR spectra of YE extract showed the vibrational peaks corresponding to these molecules. The FT-IR spectrum of control sample showed the broad vibrational peak at $3062 \mathrm{~cm}^{-1}$ that may be due to $\mathrm{O}-\mathrm{H}$ groups of amino acids. This peak was appeared at the downstream frequency region i.e. at $2983 \mathrm{~cm}^{-1}$ in the treated sample. It is well reported that the stretching frequency of vibrational peaks is directly proportional to the force constant $[31,32]$. Based on this, it is presumed that biofield energy treatment might decrease the dipole moment of $\mathrm{O}-\mathrm{H}$ bond in the treated sample of $\mathrm{YE}$ powder with respect to the control. Hence, the force constant and bond strength of $\mathrm{O}-\mathrm{H}$ group might be decreased in the treated sample as compared to the control. The vibration peaks at $2895 \mathrm{~cm}^{-1}$ and $2815 \mathrm{~cm}^{-1}$ in the control sample might be attributed to the $\mathrm{C}-\mathrm{H}$ (aliphatic) stretching. These peaks were slightly shifted correspondingly to $2883 \mathrm{~cm}^{-1}$ and $2831 \mathrm{~cm}^{-1}$ in the treated sample. This suggested the alteration in the bond 
strength of $\mathrm{CH}_{3}$ and $\mathrm{CH}_{2}$ functional groups after the biofield treatment with respect to the control [31]. The IR frequency at $1525-1577 \mathrm{~cm}^{-1}$ in the control sample and $1525-1579 \mathrm{~cm}^{-1}$ in the treated sample might be due to $\mathrm{C}=\mathrm{C}$ stretching of aromatic ring. The IR peaks at $1344-1400 \mathrm{~cm}^{-1}$ in control and 1346$1402 \mathrm{~cm}^{-1}$ in the treated sample might be due to the $\mathrm{CH}_{3}$ and $\mathrm{CH}_{2}$ deformation. The peak at $1230 \mathrm{~cm}^{-1}$ in the control sample might be due to $\mathrm{C}-\mathrm{N}$ stretching. This peak was shifted to higher frequency region i.e. at $1242 \mathrm{~cm}^{-1}$ in the treated sample. This showed the increase in the bond strength of $\mathrm{C}-\mathrm{N}$ bond in the treated sample with respect to the control. Similarly, the IR peaks observed at $1062-1147 \mathrm{~cm}^{-1}$ in the control sample might be due to C-O stretching of amino acids [33].

These peaks were correspondingly shifted to 1072-1149 $\mathrm{cm}^{-1}$ in the treated sample of YE powder. Further, the IR peaks appeared at $771-921 \mathrm{~cm}^{-1}$ in control sample and 772$921 \mathrm{~cm}^{-1}$ in the treated sample might be due to the $\mathrm{C}-\mathrm{H}$ out of plane ring bending. Likewise, the IR peaks at $534 \mathrm{~cm}^{-1}$ in control and $532 \mathrm{~cm}^{-1}$ in treated sample might be due to $\mathrm{C}=\mathrm{C}$ out of plane ring deformation [34]. Hence, the FT-IR results indicated the impact of biofield energy treatment probably on bond strength and force constant of functional groups such as $\mathrm{O}-\mathrm{H}, \mathrm{C}-\mathrm{H}, \mathrm{C}-\mathrm{N}$, and $\mathrm{C}-\mathrm{O}$ in the treated sample with respect to the control.

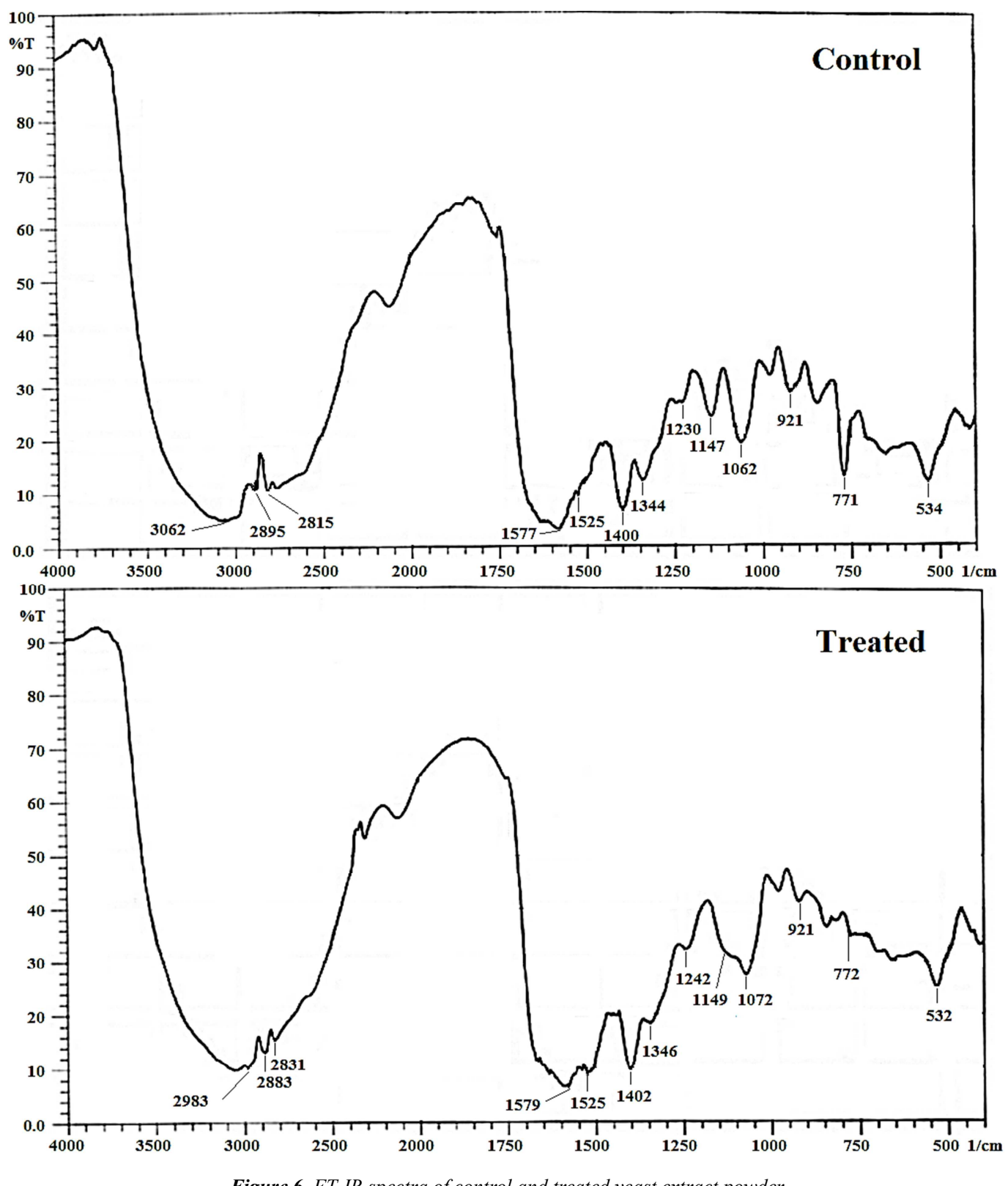

\subsection{UV-Vis Spectroscopic Characterization}

The UV spectra of the control and treated YE powder are presented in Fig. 7. The UV spectra of both the control and treated YE powder samples showed the same absorbance maxima $\left(\lambda_{\max }\right)$ at $260 \mathrm{~nm}$. It is well known that the UV absorbance occurred due to excitation of electrons from highest energy occupied molecular orbital (HOMO) to lowest energy unoccupied molecular orbital (LUMO) [31]. The 
present study result showed the no change in the $\lambda_{\max }$ of treated sample with respect to the control. This suggested that energy gap between the HOMO and LUMO in the treated sample was not altered with respect to the control.

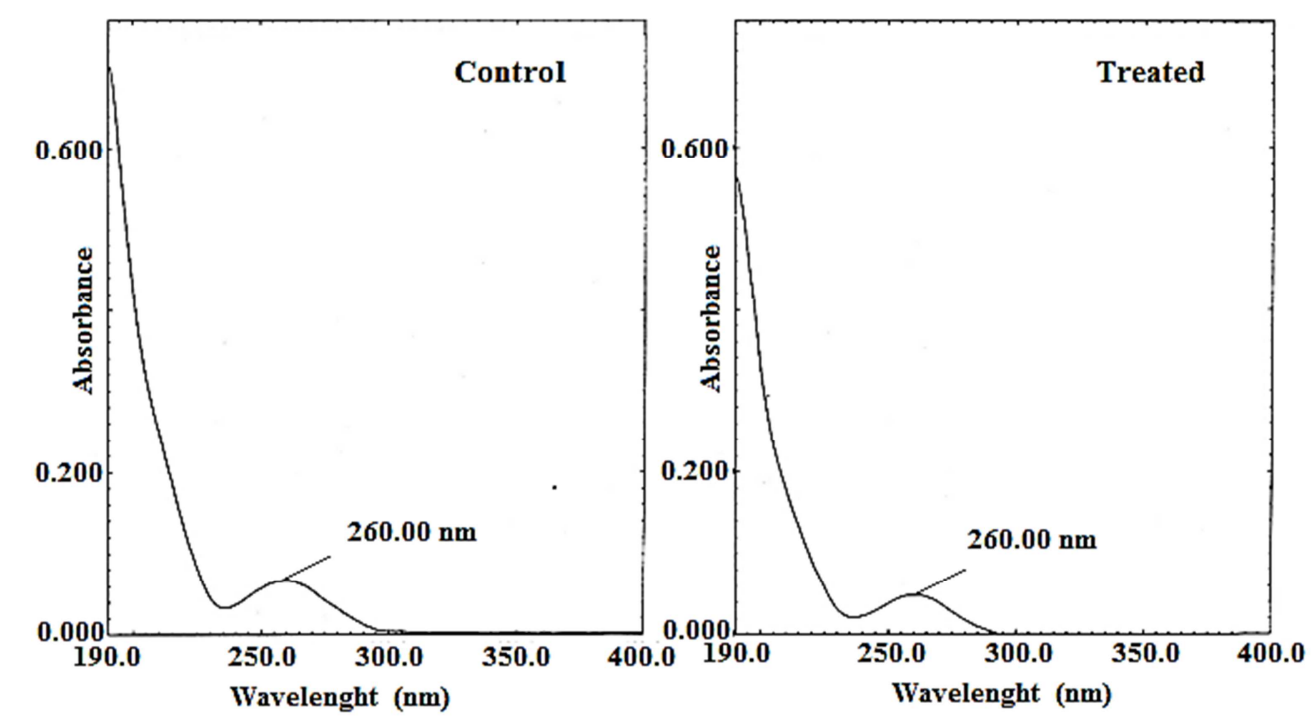

Figure 7. UV spectra of control and treated yeast extract powder.

\section{Summing-up}

The XRD study showed the amorphous nature of YE powder in both the control and treated samples. The particle size analysis revealed the increase in particle sizes i.e. $\mathrm{d}_{50}$ $(4.77 \%)$ and $d_{99}(26.28 \%)$ of the treated YE powder as compared to the control. The surface area analysis exhibited the increase $(14.06 \%)$ in the effective surface area after the biofield energy treatment with respect to the control. The DSC analysis exhibited the substantial increase in the melting temperature of treated sample by $41.64 \%$ with respect to the control. The TGA/DTG analysis showed the considerable increase in $\mathrm{T}_{\text {onset }}$ by $7.51 \%$ and $12.45 \%$ in first and second step of thermal degradation, respectively in the treated sample as compared to the control. Further, the $\mathrm{T}_{\max }$ was also increased by $4.16 \%$ and $24.79 \%$ in first and second step of thermal degradation, respectively in the treated sample with respect to the control. This showed the enhancement in thermal stability of the treated sample as compared to the control. The FT-IR study showed the alteration in wavenumber of bonds such as $\mathrm{O}-\mathrm{H}, \mathrm{C}-\mathrm{H}, \mathrm{C}-\mathrm{N}$, and $\mathrm{C}-\mathrm{O}$ after the biofield energy treatment with respect to the control.

The above findings conclude that Mr. Trivedi's biofield energy treatment had the substantial impact on the physicochemical and spectroscopic properties of YE powder. Based on this, it is anticipated that the biofield energy treated YE powder could be used as a better component of culture media than the control.

\section{Abbreviations}

NCCAM: National Center for Complementary and Alternative Medicine; XRD: X-ray diffraction; TGA: Thermogravimetric Analysis; DTG: Derivative Thermogravimetry

\section{Acknowledgments}

The authors would like to thank the entire scientific team of MGV pharmacy college, Nashik for permitting the instrumental facility. Authors also like to acknowledge the Trivedi Master Wellness, Trivedi Testimonials, and Trivedi Science for the consistent support during the study.

\section{References}

[1] http://www.tokue.com/ProductPDF/MS001\%20Mycoplasma\%20SupplementG.pdf

[2] Simpson RJ (2011) Preparation of extracts from yeast. Cold Spring Harb Protoc.

[3] De Palma Revillion JP, Brandelli A, Zachia Ayub MA (2003) Production of yeast extract from whey using $K$. marxianus. Braz Arch Biol Technol 46: 121-127.

[4] Nagodasithana T (1992) Yeast-derived flavors and flavor enhancers and their probable mode of action. Food Technol 46: 138-144.

[5] http://himedialabs.com/TD/RM027.pdf

[6] Akiyama S, Doi M, Arai Y, Nakoa Y, Fukuda H (1975) Production of yeast biomass. US patent 3,909,532.

[7] http://articles.mercola.com/sites/articles/archive/2009/04/21/m sg-is-this-silent-killer-lurking-in-your-kitchen-cabinets.aspx

[8] Kokate C, Jalalpure SS, Hurakadle PL (2011) Textbook of pharmaceutical biotechnology. Elsevier, India.

[9] Basu S, Pal A, Desai PK (2005) Quality control of culture media in a microbiology laboratory. Ind J Med Microbiol 23: 159-163. 
[10] Tabish SA (2008) Complementary and alternative healthcare: Is it evidence-based? Int J Health Sci (Qassim) 2: V-IX.

[11] Rindfleisch JA (2010) Biofield therapies: Energy medicine and primary care. Prim Care 37: 165-179.

[12] Moore RJ (2012) Handbook of pain and palliative care: Biobehavioral approaches for the life course. Springer science \& business media, LLC, New York.

[13] Trivedi MK, Patil S, Shettigar H, Mondal SC, Jana S (2015) An impact of biofield treatment: Antimycobacterial susceptibility potential using BACTEC 460/MGIT-TB system. Mycobact Dis 5: 189.

[14] Patil SA, Nayak GB, Barve SS, Tembe RP, Khan RR (2012) Impact of biofield treatment on growth and anatomical characteristics of Pogostemon cablin (Benth.). Biotechnology 11: 154-162.

[15] Sances F, Flora E, Patil S, Spence A, Shinde V (2013) Impact of Biofield treatment on ginseng and organic blueberry yield. Agrivita J Agric Sci 35: 22-29.

[16] Rubik B (1995) Energy medicine and the unifying concept of information. Altern Ther Health Med 1: 34-39.

[17] Jahn RG, Dunne BJ (1988) Margins of reality: The role of consciousness in the physical world. San Diego, CA: Harcourt Brace Jovanovich.

[18] Rosch PJ (2009) Bioelectromagnetic and subtle energy medicine. The Interface between mind and matter. Longevity, regeneration and optimal health, New York Academy of Science.

[19] Trivedi MK, Patil S, Shettigar H, Singh R, Jana S (2015) An impact of biofield treatment on spectroscopic characterization of pharmaceutical compounds. Mod Chem Appl 3: 159.

[20] Trivedi MK, Nayak G, Patil S, Tallapragada RM, Jana S, et al. (2015) Bio-field treatment: An effective strategy to improve the quality of beef extract and meat infusion powder. J Nutr Food Sci 5: 389.

[21] Chauhan A, Chauhan P (2014) Powder XRD technique and its applications in science and technology. J Anal Bioanal Tech 5: 212.
[22] http://www.britannica.com/science/amorphous-solid

[23] Gad SC (2008) Pharmaceutical manufacturing handbook: Production and processes. John Wiley \& Sons, Inc., Publication, New Jersey, USA.

[24] Trivedi MK, Patil S, Mishra RK, Jana S (2015) Thermal and physical properties of biofield treated bile salt and proteose peptone. J Anal Bioanal Tech 6: 256.

[25] Groza JR, Shackelford JF (2007) Materials processing handbook. Taylor and Francis group, CRC Press.

[26] Suttiponparnit K, Jiang J, Sahu M, Suvachittanont S, Charinpanitkul T, et al. (2011) Role of surface area, primary particle size, and crystal phase on titanium dioxide nanoparticle dispersion properties. Nanoscale Res Lett 6: 27.

[27] Paradkar AR, Bakliwal S (2008) Biopharmaceutics and pharmacokinetics. (3rdedn), Pragati Books Pvt. Ltd., Pune, India.

[28] Kumar S, Tsai CJ, Nussinov R (2000) Factors enhancing protein thermostability. Protein Eng 13: 179-191.

[29] Qi WH, Wang MP (2004) Size and shape dependent melting temperature of metallic nanoparticles. Mater Chem Phys 88: 280-284.

[30] DeVito SC, Farris CA (1997) Premanufacture notification: Chemistry assistance for submitters. John Wiley \& Sons, INC., New York, USA.

[31] Pavia DL, Lampman GM, Kriz GS (2001) Introduction to spectroscopy. (3rdedn), Thomson Learning, Singapore.

[32] Smith BC (1998) Infrared spectral interpretation: A systematic approach. CRC Press.

[33] Barth A (2000) The infrared absorption of amino acid side chains. Prog Biophys Mol Biol 74: 141-173.

[34] Geetha SK, Perumal R, Babu SM, Anbarasan PM (2006) Habit modification and improvement in properties of potassium hydrogen phthalate (KAP) crystals doped with metal ions. Cryst Res Technol 41: 221-224. 